\title{
COVID-19: Scarring Body and Mind
}

\author{
Julian Kozlowski, Senior Economist
}

W

hat are the long-run economic costs of

COVID-19? While the virus will eventually

pass, an event of this magnitude could leave

lasting effects. A shift in confidence and fear could prevent firms and consumers from rebounding to their old investment and spending habits. A recent paper (Kozlowski, Veldkamp, and Venkateswaran, 2020a) formalizes this discussion and quantifies these effects. The authors use a standard economic and epidemiological framework, with one novel channel: a "scarring effect." Scarring is a persistent change in beliefs about the probability of an extreme, negative shock to the economy.

"Belief scarring" from the COVID-19 pandemic may generate prolonged effects on the economy-with economic costs greater than the drop in GDP in 2020.

Perception can be everything: People observe new events and use these experiences to inform their expectations. For example, if you haven't seen many pandemics, you think pandemics are rare. However, when you see a pandemic, you come to believe that pandemics are not as rare as you previously thought. As an analogy, imagine you see the outcome of many rolls of a die. You don't know how many sides the die has or if the sides are weighted. However, you see numbers one through six come up many times, about equally, so you think this is a standard six-sided die. One time, though, a seven comes up. As a result, you revise your belief and now think the die has at least seven sides. Even if you don't see a seven again, the knowledge that the number seven can be rolled stays with you. It would probably affect your willingness to bet on the outcome of a die roll, too. Seeing the COVID-19 pandemic was like seeing a seven come up on what you thought was a sixsided die.

Consciously or not, we all use past events to inform our beliefs, like econometricians do. Rare events are those

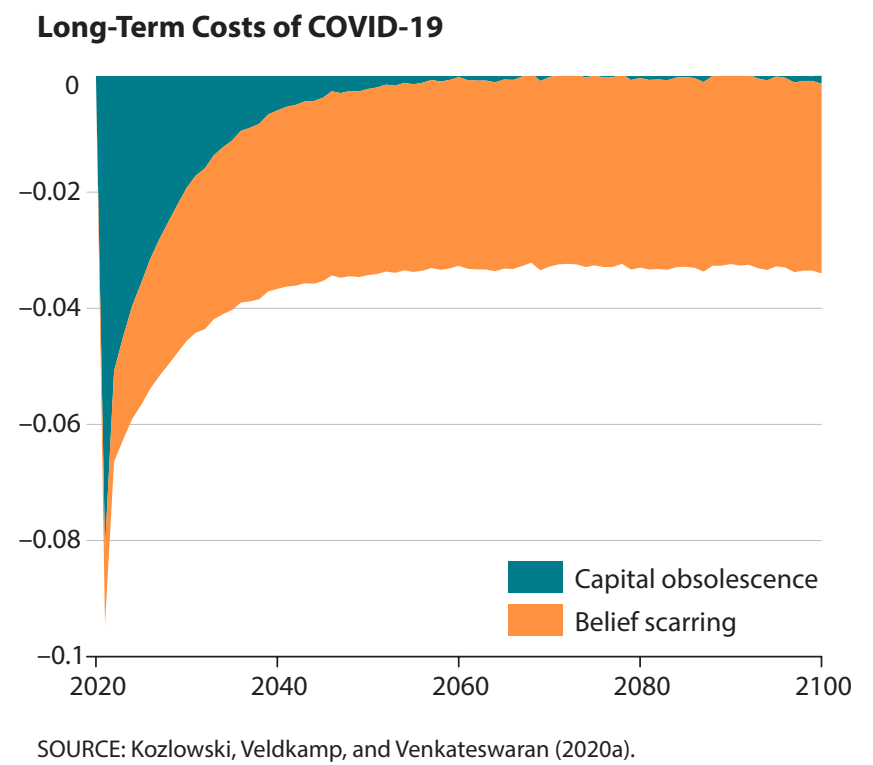

for which we have little data. In turn, the scarcity of data makes new rare events particularly informative, so rare events trigger larger belief revisions. Furthermore, because it will take many more observations of non-rare events to convince someone that a rare event really is unlikely, these changes in expectations are particularly persistent. ${ }^{1}$

The work by Kozlowski, Veldkamp, and Venkateswaran (2020a) embeds a belief-updating tool in a macroeconomic model with epidemics. Belief updating can generate large and persistent economic losses well after an epidemic is over because agents think that epidemics are more likely after seeing one. The figure shows predictions about the response to the COVID-19 crisis. GDP drops 9 percent in 2020 and recovers gradually but does not go back to its previous trajectory. It persistently remains 4 percent below the pre-COVID steady state. The discounted value of the lost output over the future is almost 10 times the 2020 drop, and belief revisions account for the bulk of the losses.

The negative economic effects of the pandemic come from two sources: capital obsolescence and belief scarring. The pandemic and lockdowns forced consumers to work and consume differently, which can generate persistent changes in tastes and habits for years to come. Capital obsolescence reflects this long-lasting change in the economic 
value of installed capital. For example, in the post-pandemic world there might be more online shopping instead of in-store purchases. Hence, some installed capital, for example, commercial real estate such as shopping malls, could become obsolete. ${ }^{2}$ The blue area in the figure shows that capital obsolescence accounts for most of the initial economic impact of the pandemic, and its net present value is equivalent to about 38 percent of 2019 GDP.

Beliefs scarring explains most of the long-term costs. For example, in the post-pandemic world, investors in leisure and hospitality, such as restaurant owners, will take into account the risk of future pandemics and lockdowns and the associated economic costs. The orange area in the figure shows that the net present value of belief scarring is about 52 percent of 2019 GDP. Hence, both capital obsolescence and belief scarring generate prolonged effects on the economy-a much larger value than the initial 9 percent drop of GDP in 2020 .

\section{Notes}

1 We have seen the scarring effect in action before. Previous Economic Synopses (Kozlowski, 2019a-c) have shown the Great Recession of 2008 generated a persistent increase in "tail risk" that had large economic costs and affected the return on safe and liquid assets. See also Kozlowski, Veldkamp, Venkateswaran (2020b).

2 Think about the loss of specific investments or other forms of lasting damage from a prolonged shutdown. Such loss could come from the lost value of cruise ships that never sail again or businesses that never reopen, loss of customer capital, or just less-intensive use of commercial space due to a persistent preference for more distance between other diners, travelers, spectators, or shoppers. It could also represent permanent changes in health and safety regulations that make transactions safer but costlier.

\section{References}

Kozlowski, Julian. "Tail Risk: Part 1, The Persistent Effects of the Great Recession." Federal Reserve Bank of St. Louis Economic Synopses, No. 18, 2019a; https://research.stlouisfed.org/publications/economic-synopses/2019/08/05/ tail-risk-part-1-the-persistent-effects-of-the-great-recession.

Kozlowski, Julian. "Tail Risk: Part 2, The Missing Recovery After the Great Recession." Federal Reserve Bank of St. Louis Economic Synopses, No. 19, 2019b; https://research.stlouisfed.org/publications/economic-synopses/2019/08/06/ tail-risk-part-2-the-missing-recovery-after-the-great-recession.

Kozlowski, Julian. "Tail Risk: Part 3, The Return on Safe and Liquid Assets." Federal Reserve Bank of St. Louis Economic Synopses, No. 20, 2019c; https://research.stlouisfed.org/publications/economic-synopses/2019/08/07/ tail-risk-part-3-the-return-on-safe-and-liquid-assets.

Kozlowski, Julian; Veldkamp, Laura and Venkateswaran, Venky. "Scarring Body and Mind: The Long-Term Belief-Scarring Effects of COVID-19." Jackson Hole Economic Policy Symposium Proceedings, 2020a; https://www.kansascityfed.org/ /media/files/publicat/sympos/2020/20200806veldkamp.pdf?la=en.

Kozlowski, Julian; Veldkamp, Laura and Venkateswaran, Venky. "The Tail that Wags the Economy: Belief-Driven Business Cycles and Persistent Stagnation." Journal of Political Economy, 2020b, 128(8). 